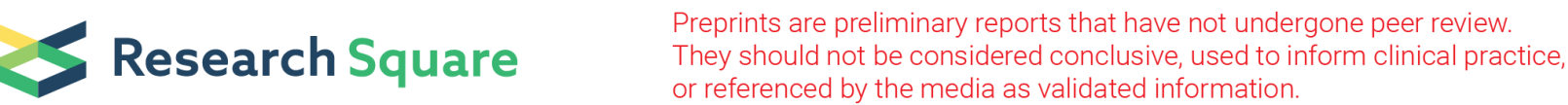

\section{Correlates of Non-Participation in Mass Drug Administration Against Neglected Tropical Diseases in the Assin North Municipality in the Central Region of Ghana}

James Akazili ( $\sim$ jakazili@gmail.com )

Ghana Health Service and C.K. Tedam University of Technology and Applied Sciences

Isaiah Agoringya

University of Health and Allied Sciences

Edmund Wedam Kanmiki

The University of Queensland https://orcid.org/0000-0001-7175-5222

Maame Woode

Monash University

Bright Alomatu

Ghana Health Service

Mike Osei-Atweneboa

Council for Scientific and Industrial Research

Rachael Thomson

Liverpool School of Tropical Medicine

Pamela Selormey

Council of Scientific \& Industrial Research

Jahangir A. M. Khan

Liverpool School of Tropical Medicine

Research article

Keywords: Mass Drug Administration, Neglected Tropical Diseases, non-participation, Ghana

Posted Date: March 31st, 2021

DOI: https://doi.org/10.21203/rs.3.rs-366390/v1

License: (1) This work is licensed under a Creative Commons Attribution 4.0 International License.

Read Full License 


\section{Abstract}

Background: Many countries in Africa are making progress towards reducing the incidence of Neglected Tropical Diseases (NTDs) and possibly eliminating them completely. Through the accepted global strategy of Mass Drug Administration (MDA), the COUNTDOWN project ${ }^{1}$ has made significant attempts through a partnership with the Ghana Health Service to reduce the incidence and impact of NTDs particularly Schistosomiasis (SCH), Soil Transmitted Helminths (STH), Onchocerciasis (OV), and Lymphatic Filariasis (LF) in Ghana. However, elimination can be achieved only when the key players including the community members comply with the programme guidelines and requirements by participating in MDA campaigns against NTDs. The objective of the paper is to examine the factors influencing community members' participation in MDA programs that seeks to bring the services of NTDs prevention to the doorstep of individuals.

Methods: We used a population-based survey data of 1,034 people from 296 households collected in the Assin North Municipality in the Central Region of Ghana. First, chi-square test was used to test the association of socio-economic factors and participation in MDAs. Subsequently, we ran a multilevel logistic regression model to estimate the association of factors that influence non-participation in MDA by community members.

Results: Nearly a quarter of respondents had once suffered from STH (22.5\%) and a small fraction from bilharzia (7.4), river blindness (1.1\%), and nobody suffered from LF. Although almost all respondents $(97 \%)$ had ever heard of MDA campaign, $22 \%$ of respondents missed or did not participate in a MDA program. Factors that were found to correlate with non-participation in MDA programs are marital status and previously receiving tablets from a MDA campaign.

Conclusion: Results showed that MDA participation by community members is relatively high and thus Ghana's efforts at eliminating NTDs through MDA is on course. However, continues public education is required to maintain high participation and possibly improve upon it.

${ }^{1}$ The project looks at the parasitological, epidemiological as well as the socio-economic factors that influence the acceptance, effectiveness, efficiency and equity impact of scale-up from a health systems approach

\section{Background}

Globally, over 1 billion people living in developing countries are affected by Neglected Tropical Diseases (NTDs) [1]. Sub-Saharan Africa alone loses an estimated 5.9 million years of healthy lives annually due to NTDs like schistosomiasis (SCH), soil-transmitted helminthiasis (STH), onchocerciasis (ONCHO) and lymphatic filariasis (LF) [2-4]. NTDs are known to affect the most marginalized and poorest who often lack access to treatment and preventive care $[3,5,6]$. 
Mass Drug Administration (MDA) is a means of delivering safe and essential medicines based on the principles of preventive chemotherapy, where populations or sub-populations are offered treatment without individual diagnosis [7]. MDA is the recommended strategy of the WHO to control or eliminate several NTDs [8]. Globally more than 1.5 billion people now receive these essential medicines through MDAs for at least one of the five NTDs annually [8].

MDA is a means to help reduce the burden of disease, and hence poverty, among the poorest segments of populations. It has already made significant improvements to global health and productivity and has the potential for further success with the active participation of the affected population. Many countries in Africa are making progress towards reducing the incidence of NTDs and even their possible complete elimination $[5,9]$. To eliminate NTDs within the coming two decades, an additional minimum of 1.9 billion people need to receive MDA annually over several years [7].

With recent impressive economic growth and development, Ghana is expecting a decline in the prevalence and disease burden of the NTDs and other poverty-related neglected diseases. Indeed, guinea worm, human African trypanosomiasis, and trachoma have recently been eliminated in Ghana, and there have been steep declines in the prevalence of onchocerciasis and lymphatic filariasis (as well as oesophogostomiasis and yaws), with the prospect of eliminating these diseases as well in the near future [10]. Through the accepted global strategy of MDA, the COUNTDOWN project ${ }^{2}$ has recently made significant attempts through a partnership with the Ghana Health Service to reduce the incidence and impact of NTDs particularly SCH, STH, ONCHO, and LF in Ghana. However, elimination can be achieved only when the key players including the community members participate in and comply with the programme guidelines and requirements to ensure effective MDAs to achieve the intended outcomes.

Ghana has adopted the implementation of MDA as the main strategy for the control or elimination of NTDs such as elephantiasis, river blindness, bilharzia and intestinal worm infestation in all endemic districts for the elimination of NTDs [11]. Ghana's NTD program has made good progress, particularly against trachoma which has been eliminated, and LF which is on the verge of elimination as a disease of public health importance through MDA. However, lack of awareness, unsafe health practices, and limited access to safe water and sanitation continue to present challenges to the fight against NTDs. NTDs such as LF, SCH, Oncho and Soil Transmitted Helminths (STH) continue to threaten the health and wellbeing of people in parts of Ghana $[12,13]$ where endemic populations continue to miss MDAs. Given the wellknown importance of MDA for eliminating NTDs it is important to gain an understanding as to which segments of the population get missed during MDAs so as to better tailor appropriate interventions aimed at improving their access to MDA programs. The objectives of this paper are therefore to $i$ ) assess the endemicity of four main NTDs i.e STH, Shisto, Oncho \& LF ii) understand the health-seeking behavior of people who report having had NTDs iii) assess the prevalence of missing MDA campaign programs and iv) examine the determinants of missing MDA campaigns. We believe that this knowledge would contribute to the MDA programs and policy interventions aiming at optimizing the use of MDA for dealing with NTDs in Ghana and other countries in similar settings. 
${ }^{2}$ The project looks at the parasitological, epidemiological as well as the socio-economic factors that influence the acceptance, effectiveness, efficiency and equity impact of scale-up from a health systems approach

\section{Methods}

\section{Study setting}

Data used in this study was collected from the Assin North Municipality in the Central Region of Ghana. This municipality is one of the 20 districts/municipals/metropolitans in the Central region. It has an estimated population of 190,219 . The main economic activities of the people in the district are farming (which employs $63 \%$ of the population), Trading and agro-processing. In terms of health care access, the municipality is divided into six sub municipals with health centres. It has a mission hospital, two maternity homes, a private clinic and twelve Community-based Health and Planning Services (CHPS) compounds. The Municipal has 110 pre-schools, 111 primary schools, 77 junior high schools, 4 senior high schools and 1 college of education.

\section{Data collection and analysis}

A total of six data collectors were recruited and given 5 days of training prior to the data collection. Training took place from the 23rd to the 27th of July 2018. The data collection instrument was first pretested which enabled appropriate revisions of the study tools before actual data collection. Data collection took place in August 2018. A total of 296 households were targeted and interviewed. The interviewers collected information on the background and socio-economic characteristics of study participants, their knowledge of NTDs and MDA campaigns, their involvement in MDAs, whether they had ever missed an MDA and their compliance with MDAs. Information on their general health including ever suffering from the common NTDs in Ghana was also collected. For this paper, the variable of interest is the incidence of missing or non-participation in a MDA. Descriptive statistics are used to describe the study participants' characteristics and their knowledge and participation in MDA while bivariate analysis using chi-square test of association and multilevel regression analysis is used to assess the factors influencing non-participation in MDA. The first level was the community variable and the second level was the household.

\section{Results}

\section{Descriptive Statistics}

A total of 1,034 individuals from the 258 households were interviewed during the survey. Two groups of respondents were interviewed in this study. The first group was the household head who respondent to household related questions. The second group was respondents who responded to NTD and MDA related questions. 
From Table 1, it can be observed that about $69 \%$ of the household heads were males, $61 \%$ were married and a majority (57.4\%) were between the ages of 35-64 years. More than half $(56 \%)$ of the households were rural dwellers and a majority $(70 \%)$ had up to secondary level of education. It can also be observed that less than half $(41 \%)$ of the household heads were covered by the national health insurance scheme.

About 444 household members responded to questions on NTD and MDA activities. Out of the 444 respondents, about $37 \%$ were in the $20-34$ year age group whilst about $40 \%$ in the $35-64$ year age group. About $62 \%$ of the respondents were females, $31 \%$ were married, $47 \%$ were covered by the national health insurance scheme and $71 \%$ had attained education to the secondary level.

\section{Knowledge of NTDs and MDA activities}

Table 2 presents information about the knowledge of respondents on NTDs and MDA activities. A total of four hundred and forty-four (444) people were interviewed, a small proportion (15\%) of the respondents indicated they ever heard of NTD and about $98 \%$ indicated they ever heard of MDA. Most $(94.4 \%)$ of the respondents knew that MDAs take place in their community. About $49 \%$ of the respondents indicated they received tablets during the last MDA, whilst $24.3 \%$ stated they received tablets a year before the last MDA. Only $7.9 \%$ of 216 respondents suffered side effects after an MDA medication. A little above half (53.2\%) of respondents who are aware of MDA in their community indicated that they ever missed a MDA campaign.

Knowledge of CDD was high among respondents. Close to eighty-two percent ever heard of CDD and whilst $93.2 \%$ indicated that a CDD was assigned to their community or household. $79.2 \%$ knew that CDD gives drugs at different times of the year and $93.2 \%$ indicated they ever dealt with a CDD in their community or household.

Concerning STH, bilharzia and river blindness, less than thirty percent ever suffered from STH (22.5\%), bilharzia (7.4\%) and river blindness (1.1\%). Nearly all respondents (98\%) who had STH sought treatment. All respondents who had river blindness sought treatment and about $91 \%$ seeking treatment for bilharzia. None of the respondents suffered from schistosomiasis and only $0.7 \%$ of those who are aware CDD gives drugs at different times of the year ever decided to stop taking medication due to CDD interference.

Among those who indicated that they have ever had STH disease, $51 \%$ had it less than three months ago, $59 \%$ of them had it less than 6 months ago and $66 \%$ of them had it within a year or less whiles $26 \%$ had it over a year ago. Of the number of study participants who suffered from STH and sought care, $25 \%$ of them were within the richest socio-economic status quintile while $12 \%$ were within the poorest quintile; there was a gradual decrease in percentage who sought care by decreasing socio-economic status.

\section{Bivariate analysis of missing MDA}

Table 3 presents the bivariate analysis using chi-square test of association to explore the factors associated with non-participation in MDA campaigns. Only age $(P$-value $=0.002)$ and ever receiving albendazole (P-value <0.01) tablets were found to be significantly associated with ever missing MDA 
campaign. Whiles, The rest of the demographic variables were not significantly associated with ever missing MDA campaign. Also, knowledge on NTDs and MDA activies such as ever suffered from STH, ever suffered from Shisto and knowledge of CDDs were not significantly associated with ever missing MDA campaign.

Table 4 represents results on a multilevel logistic regression that sought to identify some predictors on non-participation of individuals in MDA campaigns. Clustering around communities and households was also taken into account in identifying potential predictors. Marital status and ever receiving Albendazole tablets were the only two factors significantly associated with participation in MDAs. Respondents who never married were 7.17 times more likely to miss an MDA exercise compared to those who were either divorced, separated or widowed [OR= 7.17 (95\% C.I; 1.07, 47.95), $p=0.042$ ] whilst those who have received albendazole tablets previously were 22.23 times more likely to miss an MDA exercise compared to those who did not receive any tablets in previous MDAs [OR=22.23 (95\% C.l; 3.33, 148.42), $p=0.001$ ].

\section{Discussion}

Mass Drug Administration (MDA) is a key strategy recommended by the World Health Organisation for the eradication of most NTDs globally. NTDs generally affect the vulnerable and marginalized. These groups of affected individuals often lack access to treatment [3]. MDAs come in handy to bridge the gap of access. Previous studies have identified the distribution of the share of most NTDs by global economic ranking and found out that the share of the burden of the NTDs is concentrated in low and lower-middleincome countries [14]. The share of the burden for schistosomiasis in low-and-middle-income countries was found to be around $80 \%$ whilst that for onchocerciasis was $90-100 \%$. The burden of the share of STH was found to be higher in upper-middle-income countries compared to lower-income countries [14]. Our study however shows a relatively higher burden of STH in Ghana, a LMIC.

This paper aims at providing an understanding of the incidence of NTDs, health-seeking behavior of people who fall sick of selected NTDs and the key factors associated with community members' participation in MDA programs that aims at bringing NTD prevention services to the doorstep of community members. The study adopted a cross-sectional survey of selected households. Our results show that nearly a quarter of respondents had once suffered from STH and a small fraction from bilharzia and river blindness. Also, more people in the relatively riches socio-economic status seek treatment for STH compared to those in the poorest socio-economic status ( $25 \%$ vrs $12 \%$ ) and the rate of self-treatment for STH was quite high among the study population (86\%).

Nearly all respondents had heard of MDA while slightly more than half reported ever missing an MDA. We conducted a multilevel regression analysis to identify potential factors associated with community member's participation in MDA. We considered a p-value less than 0.05 as statistical significance. Results from regression analysis showed that only marital status and ever received albendazole was significantly associated with community member's participation in MDAs. The rest of the variables showed some level of association but were not statistically significant. 
Despite the established benefits of MDA as a strategy for the elimination of community diseases especially NTDs, the gains achieved through MDA are marred by some challenges and this affects coverage of MDA at community level. Our study unlike other studies who identified challenges of MDA relating to biological factors including drug resistance to NTDs [7], focused on the socio-demographic and economic challenges. In another study in Ghana by Manyeh et al 2019, an array of challenges were identified to have negatively affected filariasis and MDAs [15]. The challenges identified included; knowledge of LF \& MDA among drug distributors, social mobilization \& sensitization, drug distribution process, adverse drug reactions, non-compliant community members, non-adherence to the DOT strategy, and non-involvement of community leaders and other stakeholders [15]. Secor et al. in their comparative study of school-based treatment against community-wide Mass Drug Administration (MDA) reported that increasing the training of community drug distributors and communication efforts resulted in better coverage estimates of MDAs [16]. Krentel et al also emphasized the important role of volunteer community drug distributors in MDA campaigns [17]. Most of these studies have focused on challenges relating to the implementation of MDA, our study however has examined the challenges from the participants angle. Our findings complement previous findings to give a complete picture of the challenges that hinder community participation and consequently coverage of MDA.

Our study suggests that marital status and receiving albendazole tablets in a previous MDA is associated with individual participation in MDA and by extension MDA coverage. Even though not statistically significant, it worth noting that respondents who had previously suffered from an NTD, belong to a higher socio-economic class, ever suffered some side effects from MDA drugs were more likely to miss MDA campaigns than their counterparts. This study has provided some level of evidence to complement other studies and efforts aimed at improving MDA coverage and ultimately towards the elimination of NTDs that burden households and the health systems of LMICs. Though the MDA programme is largely successful in Ghana, the results show that there is still need for continual public education and awareness creation especially among those who previously participated in MDAs to maintain and improve participation in these campaigns.

\section{Study Limitations}

As a cross-sectional study design, this study is limited in drawing any causal inference. This study is also unable to provide an indepth understanding of the reasons for non-participation in MDA beyong correlates due to its design. In spite of these limitations, this study has contributed to the literature on the incidence of NTDs in Ghana and the socio-economic and demographic factors associated with nonparticipation MDAs.

\section{Conclusion}

The incidence of Neglected Tropical Diseases (NTDs) in developing countries still presents a great burden to the health and socio-economic development of these countries including Ghana. The importance of Mass Drug Administration (MDA) for the elimination of NTDs can not be overemphasized. Results of this 
study indicate that participation in MDA by community members is relatively high and thus Ghana's efforts at eliminating NTDs through MDA is on course. However, continuous public education is required to maintain high participation and possibly improve upon it.

\section{List Of Abbreviations}

NTDs;- Neglected Tropical Diseases, MDA;- Mass Drug Administration, SCH;- Schistosomiasis, STH;- Soil Transmitted Helminths, ONCHO;- Onchocerciasis, LF;- Lymphatic Filarisis, CHPS;- Community-based Health Planning and Services

\section{Declarations}

\section{Ethical Approval and Consent to participate}

This study obtained Ethical approval from the Ghana Health Service Ethical Review Committee (GHS-ERC 16/01/2017) before commencing the study. The study team administered written informed consent to all participants including from a parent or guardian for participants under 16 years old and only those who voluntarily consented were interviewed. Confidentiality and anonymity of study participants and their information has been carefully protected during data collection, processing and report writing.

\section{Consent for publication}

Not applicable

\section{Avialability of data and materials}

The datasets used and/or analysed during the current study are available from the corresponding author on reasonable request.

\section{Competing interests}

The authors declare that they have no competing interests

\section{Funding}

This study was funded through a grant from the UKAID to the COUNTDOWN consutium under grant number: PO 6407

\section{Authors' contributions}

JA, JMK, RT and MW conceptualized and designed the study. JA, IA,JMK, EWK, RT, PS and MW conducted the study and analysised the data. JA, IA,JMK, EWK, RT, and MW wrote the paper. MO and RT reviewed the paper substantially. All authors read and approved of the final draft for publication. 


\section{Acknowledgements}

We wish to acknowledge the study participants for volunteering their time to providing us with data for this study. We also acknowledge the hard work of our data collactors for the success of this research.

\section{References}

1. World Health Organization. WHO Report on Neglected Tropical Diseases. 2010.

2. Evaluation I for HM and. GBD Data I Institute for Health Metrics and Evaluation. http://www.healthdata.org/gbd/data. Accessed 17 Jan 2020.

3. Conteh L, Engels T, Molyneux DH. Socioeconomic aspects of neglected tropical diseases. The Lancet. 2010;375:239-47.

4. Woode M, Khan J, Thomson R, Open LN-B, $2018 \mathrm{U}$. Equity and efficiency in the scaled-up implementation of integrated neglected tropical disease control: the health economics protocol of the COUNTDOWN. bmjopen.bmj.com. 2017. https://bmjopen.bmj.com/content/8/6/e020113.abstract. Accessed 17 Jan 2020.

5. Hotez PJ, Fenwick A, Savioli L, Molyneux DH. Rescuing the bottom billion through control of neglected tropical diseases. The Lancet. 2009;373:1570-5.

6. Hotez PJ, Kamath A. Neglected tropical diseases in sub-Saharan Africa: Review of their prevalence, distribution, and disease burden. PLoS Neglected Tropical Diseases. 2009;3.

7. Webster JP, Molyneux DH, Hotez PJ, Fenwick A. The contribution of mass drug administration to global health: Past, present and future. Philosophical Transactions of the Royal Society B: Biological Sciences. 2014;369. doi:10.1098/rstb.2013.0434.

8. World Health Organization. Global Programme to Eliminate Lymphatic Filariasis. WHO. 2017.

9. Moeti M. Africa: The Elimination of Neglected Tropical Diseases Is Finally Within Reach | WHO | Regional Office for Africa. https://www.afro.who.int/media-centre/statements-commentaries/africaelimination-neglected-tropical-diseases-finally-within. Accessed 17 Jan 2020.

10. Biritwum NK, Frempong KK, Verver S, Odoom S, Alomatu B, Asiedu O, et al. Progress towards lymphatic filariasis elimination in Ghana from 2000-2016: Analysis of microfilaria prevalence data from 430 communities. PLoS Negl Trop Dis. 2019;13:e0007115. doi:10.1371/journal.pntd.0007115.

11. Biritwum N-K, de Souza DK, Marfo B, Odoom S, Alomatu B, Asiedu O, et al. Fifteen years of programme implementation for the elimination of Lymphatic Filariasis in Ghana: Impact of MDA on immunoparasitological indicators. PLoS Negl Trop Dis. 2017;11:e0005280. doi:10.1371/journal.pntd.0005280.

12. Ahiadorme $M$, Morhe E. Soil transmitted helminth infections in Ghana: A ten year review. Pan African Medical Journal. 2020;35:1-16. doi:10.11604/pamj.2020.35.131.21069.

13. Adu-Gyasi D, Asante KP, Frempong MT, Gyasi DK, Iddrisu LF, Ankrah L, et al. Epidemiology of soil transmitted Helminth infections in the middle-belt of Ghana, Africa. Parasite Epidemiol Control. 
2018;3:e00071.

14. Stolk WA, Kulik MC, le Rutte EA, Jacobson J, Richardus JH, de Vlas SJ, et al. Between-Country Inequalities in the Neglected Tropical Disease Burden in 1990 and 2010, with Projections for 2020. PLoS Negl Trop Dis. 2016;10:e0004560. doi:10.1371/journal.pntd.0004560.

15. Manyeh AK, Ibisomi L, Baiden F, Chirwa T, Ramaswamy R. Using intervention mapping to design and implement quality improvement strategies towards elimination of lymphatic filariasis in Northern Ghana. PLoS Negl Trop Dis. 2019;13:e0007267. doi:10.1371/journal.pntd.0007267.

16. Secor WE, Wiegand RE, Montgomery SP, Karanja DMS, Odiere MR. Comparison of school-based and community-wide mass drug administration for schistosomiasis control in an area of western Kenya with high initial schistosoma mansoni infection prevalence: A cluster randomized trial. Am J Trop Med Hyg. 2020;102:318-27. doi:10.4269/ajtmh.19-0626.

17. Krentel A, Gyapong M, Mallya S, Boadu NY, Amuyunzu-Nyamongo M, Stephens M, et al. Review of the factors influencing the motivation of community drug distributors towards the control and elimination of neglected tropical diseases (NTDs). PLoS Negl Trop Dis. 2017;11:e0006065. doi:10.1371/journal.pntd.0006065.

\section{Tables}


Table 1

Demographic characteristics of study respondents

\begin{tabular}{|c|c|c|c|c|c|}
\hline \multirow[b]{2}{*}{ Main Variable } & \multirow[b]{2}{*}{ Variable option } & \multicolumn{2}{|c|}{$\begin{array}{l}\text { Household } \\
\text { heads }\end{array}$} & \multicolumn{2}{|c|}{$\begin{array}{l}\text { Respondents of NTDs and MDAs } \\
\text { questions }\end{array}$} \\
\hline & & $\mathrm{n}$ & $\%$ & $\mathrm{~N}$ & $\%$ \\
\hline \multirow[t]{5}{*}{ Age group } & $0-14$ & 0 & 0.0 & 0 & 0.0 \\
\hline & $15-19$ & 2 & 0.78 & 70 & 15.8 \\
\hline & $20-34$ & 83 & 32.6 & 164 & 36.9 \\
\hline & $35-64$ & 148 & 57.4 & 179 & 40.3 \\
\hline & $65+$ & 24 & 9.3 & 31 & 6.9 \\
\hline \multirow[t]{2}{*}{ Insurance status } & Insured & 106 & 41.1 & 208 & 46.9 \\
\hline & Not insured & 152 & 58.9 & 236 & 53.1 \\
\hline \multirow[t]{2}{*}{ Gender } & Male & 177 & 68.6 & 170 & 38.3 \\
\hline & Female & 81 & 31.4 & 274 & 61.7 \\
\hline \multirow[t]{2}{*}{ Location } & Urban & 114 & 44.2 & 209 & 47.1 \\
\hline & Rural & 144 & 55.8 & 235 & 52.9 \\
\hline \multirow[t]{3}{*}{ Marital status } & Never married & 43 & 16.3 & 237 & 53.4 \\
\hline & Married & 157 & 60.9 & 137 & 30.9 \\
\hline & Separated/widowed & 59 & 22.9 & 70 & 15.8 \\
\hline \multirow{5}{*}{$\begin{array}{l}\text { Socio-economic } \\
\text { status }\end{array}$} & Q1 Poorest & 49 & 18.9 & 67 & 15.1 \\
\hline & Q2 & 51 & 19.8 & 75 & 16.9 \\
\hline & Q3 & 53 & 20.5 & 81 & 18.2 \\
\hline & Q4 & 53 & 20.5 & 105 & 23.7 \\
\hline & Q5 Richest & 52 & 20.2 & 116 & 26.1 \\
\hline \multirow[t]{4}{*}{ Education } & $\begin{array}{l}\text { No formal } \\
\text { education }\end{array}$ & 5 & 2.10 & 11 & 2.7 \\
\hline & Primary & 34 & 14.3 & 73 & 17.8 \\
\hline & Secondary & 167 & 70.2 & 293 & 71.2 \\
\hline & Tertiary & 32 & 13.5 & 34 & 8.3 \\
\hline
\end{tabular}


Table 2

Knowledge of NTDs and MDA activities

\begin{tabular}{|llll|}
\hline & Yes \\
\hline Variable & N & $\%$ \\
\hline Ever heard of NTD & 444 & 68 & 15.3 \\
\hline Ever heard of MDA & 444 & 433 & 97.5 \\
\hline Aware MDAs take place in community & 444 & 419 & 94.4 \\
\hline Ever missed MDA & 419 & 223 & 53.2 \\
\hline Received tablets during last MDA & 444 & 216 & 48.7 \\
\hline Suffered side effects from MDA medications & 216 & 17 & 7.9 \\
\hline Received tablets a year before last MDA & 444 & 108 & 24.3 \\
\hline Ever heard of CDDs & 444 & 365 & 82.2 \\
\hline CDD assigned to your household or community & 444 & 340 & 93.2 \\
\hline CDD gives drug at different times of year & 444 & 289 & 79.2 \\
\hline Ever dealt with CDD & 444 & 340 & 93.2 \\
\hline Suffered from STH & 444 & 100 & 22.5 \\
\hline Sought treatment for STH & 100 & 98 & 98 \\
\hline Suffered from Bilharzia & 444 & 33 & 7.4 \\
\hline Sought treatment for Bilharzia & 33 & 30 & 90.9 \\
\hline Suffered from River blindness & 444 & 5 & 1.13 \\
\hline Sought treatment for River blindness & 5 & 5 & 100 \\
\hline Suffered from Elephantiasis (Schisto) & 444 & 0 & 0.0 \\
\hline Ever decided to stop taking medication due to CDD influence & 290 & 2 & 0.7 \\
\hline
\end{tabular}


Table 3

Bivariate Analysis of Ever Missing MDA Exercise

\begin{tabular}{|c|c|c|c|c|c|}
\hline \multirow{2}{*}{$\begin{array}{l}\text { Variable } \\
\text { Main Variable }\end{array}$} & \multirow[b]{2}{*}{ Variable option } & \multicolumn{2}{|c|}{$\begin{array}{l}\text { Ever missed MDA }(\mathrm{N}= \\
444)\end{array}$} & \multirow[t]{2}{*}{ Total } & \multirow[t]{2}{*}{$\begin{array}{l}P \\
\text { Value }\end{array}$} \\
\hline & & $\mathrm{n}$ & $\%$ & & \\
\hline \multirow[t]{4}{*}{ Age group $(n=419)$} & $15-19$ & 31 & 50.8 & 61 & \multirow[t]{4}{*}{0.002} \\
\hline & $20-34$ & 100 & 64.1 & 156 & \\
\hline & $35-64$ & 75 & 43.4 & 173 & \\
\hline & $65+$ & 17 & 58.6 & 29 & \\
\hline \multirow[t]{2}{*}{ Insurance status $(\mathrm{n}=1019)$} & Insured & 100 & 51 & 196 & \multirow[t]{2}{*}{0.397} \\
\hline & Not insured & 123 & 55.2 & 223 & \\
\hline \multirow{2}{*}{$\begin{array}{l}\text { Ever Suffered an NTD }(\mathrm{STH})(\mathrm{n}= \\
419)\end{array}$} & Yes & 56 & 59.6 & 94 & \multirow[t]{2}{*}{0.161} \\
\hline & No & 167 & 51.4 & 325 & \\
\hline \multirow{2}{*}{$\begin{array}{l}\text { Ever received albendazole } \\
\text { tablets }(n=419)\end{array}$} & Yes & 34 & 32.4 & 105 & \multirow[t]{2}{*}{0.000} \\
\hline & No & 189 & 60.2 & 314 & \\
\hline \multirow{2}{*}{$\begin{array}{l}\text { Experienced side effects of } \\
\text { tablets }(n=211)\end{array}$} & Yes & 2 & 12.5 & 16 & \multirow[t]{2}{*}{0.351} \\
\hline & No & 44 & 22.6 & 195 & \\
\hline \multirow[t]{2}{*}{ Heard of MDA $(n=419)$} & Yes & 221 & 53.3 & 415 & \multirow[t]{2}{*}{0.897} \\
\hline & No & 2 & 50.0 & 4 & \\
\hline \multirow[t]{2}{*}{ Heard of CDD $(n=419)$} & Yes & 180 & 51.6 & 349 & \multirow[t]{2}{*}{0.132} \\
\hline & No & 43 & 61.4 & 70 & \\
\hline \multirow[t]{2}{*}{ Gender $(n=419)$} & Male & 88 & 54.3 & 162 & \multirow[t]{2}{*}{0.720} \\
\hline & Female & 135 & 52.5 & 257 & \\
\hline \multirow[t]{2}{*}{ Location $(n=419)$} & Urban & 97 & 50.5 & 192 & \multirow[t]{2}{*}{0.308} \\
\hline & Rural & 126 & 55.5 & 227 & \\
\hline \multirow[t]{3}{*}{ Marital status $(n=419)$} & Never married & 68 & 54.4 & 125 & \multirow[t]{3}{*}{0.157} \\
\hline & Married & 126 & 55.8 & 226 & \\
\hline & Separated/widowed & 29 & 42.7 & 68 & \\
\hline \multirow{2}{*}{$\begin{array}{l}\text { Socio-economic status } \\
(\mathrm{n}=419)\end{array}$} & Q1 Poorest & 33 & 50.8 & 65 & \multirow[t]{2}{*}{0.408} \\
\hline & Q2 & 40 & 56.3 & 71 & \\
\hline
\end{tabular}




\begin{tabular}{|llllll|} 
& Q3 & 48 & 61.5 & 78 & \\
\hline Q4 & 52 & 52.0 & 100 & \\
\cline { 2 - 5 } & Q5 Richest & 50 & 47.6 & 105 & \\
\hline $\begin{array}{l}\text { No formal } \\
\text { education }\end{array}$ & 20 & 46.5 & 43 & 0.465 \\
\hline Primary & 34 & 49.3 & 69 & \\
\hline Secondary & 155 & 55.9 & 277 \\
\hline Tertiary & 14 & 46.7 & 30 \\
\hline
\end{tabular}


Table 4

Multi-variate Analysis of Ever Missing MDA Exercise

\begin{tabular}{|c|c|c|c|}
\hline MDA non-participation & Odds Ratio & p-value & $95 \%$ conf. Interval \\
\hline \multicolumn{4}{|l|}{ Sex } \\
\hline Male & ref & & \\
\hline Female & 1.774353 & 0.301 & $0.59,5.26$ \\
\hline \multicolumn{4}{|l|}{ Age group } \\
\hline $15-19$ & ref & & \\
\hline $20-34$ & 1.14 & 0.900 & $0.16,8.32$ \\
\hline $36-64$ & 9.62 & 0.073 & $0.81,114.1$ \\
\hline \multicolumn{4}{|l|}{ SES status } \\
\hline Q1 poorest & ref & & \\
\hline 2 & 0.51 & 0.548 & $0.087,4.50$ \\
\hline 3 & 0.20 & 0.121 & $0.03,1.52$ \\
\hline 4 & 2.12 & 0.478 & $0.27,16.9$ \\
\hline Q5 least poor & 21.1 & 0.127 & $0.42,9.78$ \\
\hline \multicolumn{4}{|l|}{ Education } \\
\hline No formal education & ref & & \\
\hline Primary edu & 0.43 & 0.582 & $0.20,8.93$ \\
\hline Secondary edu & 0.69 & 0.800 & $0.38,12.37$ \\
\hline Tertiary edu & 6.46 & 0.384 & $0.09,431.5$ \\
\hline \multicolumn{4}{|l|}{ Marital Status } \\
\hline Married & ref & & \\
\hline Never married & 7.17 & 0.042 & $1.07,47.95$ \\
\hline Sep/dev/wid & 0.76 & 0.709 & $0.17,3.28$ \\
\hline \multicolumn{4}{|l|}{ Had side effects } \\
\hline No & ref & & \\
\hline Yes & 5.51 & 0.149 & $0.54,56.12$ \\
\hline \multicolumn{4}{|l|}{ Ever suffered an NTD } \\
\hline No & ref & & \\
\hline
\end{tabular}




\begin{tabular}{|llll|}
\hline Yes & 2.70 & 0.169 & $0.65,11.17$ \\
\hline Received tablets in last MDA & & & \\
\hline No & ref & & \\
\hline Yes & 22.2 & 0.001 & $3.33,148.4$ \\
\hline Heard about CDD & & & \\
\hline No & ref & & \\
\hline Yes & 0.90 & 0.908 & $0.16,5.07$ \\
\hline Insurance status & & & \\
\hline Not insured & ref & & \\
\hline Insured & 0.70 & 0.525 & $0.24,2.08$ \\
\hline
\end{tabular}

